Supplement of Solid Earth, 6, 1259-1276, 2015

http://www.solid-earth.net/6/1259/2015/

doi:10.5194/se-6-1259-2015-supplement

(C) Author(s) 2015. CC Attribution 3.0 License.

(c) (i)

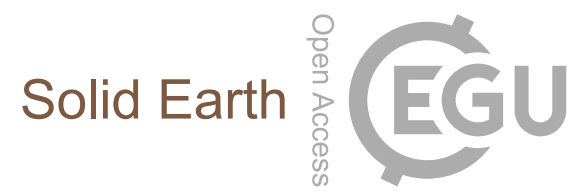

Supplement of

\title{
Geometry of the inverted Cretaceous Chañarcillo Basin based on 2-D gravity and field data - an approach to the structure of the western Central Andes of northern Chile
}

\author{
F. Martínez et al. \\ Correspondence to: F. Martínez (martinezfjh@ hotmail.com)
}

The copyright of individual parts of the supplement might differ from the CC-BY 3.0 licence. 


\section{Magnetotelluric constraints}

Magnetotelluric (MT) data measured in two sites along the northern profile is presented in this section (Figure S1). The data was aquired using broadband Metronix equipment, considering horizontal electric and magnetic field measurements, for full impedance tensor calculations. The analysis of these elements for all the MT stations measured indicated that a 1-D approximation is suitable for periods between $0.001 \mathrm{~s}$ to $1 \mathrm{~s}$.

1-D models were obtained using Winglink 2.21.02, based on Bostick and Occam types of smooth inversions, considering the fit of apparent resistivity and phase curves. The models presented here considered the fitting of the Zxy element.

Both models present similar features: A shallow and thin (approximate $10 \mathrm{~m}$ ) resistive layer (100 - $1000 \mathrm{Ohm}-\mathrm{m})$, an intermediate less resistive layer (10 - $100 \mathrm{Ohm}-\mathrm{m})$, and a resistive layer below (100-1000 Ohm-m). The intermediate layer in these models was interpreted as young sediments (quaternary), and syn-rift deposits, which overlay a much more resistive layer which was interpreted as granitic intrusives for the westernmost station (H01) and pre-rift basement for the station H13. 

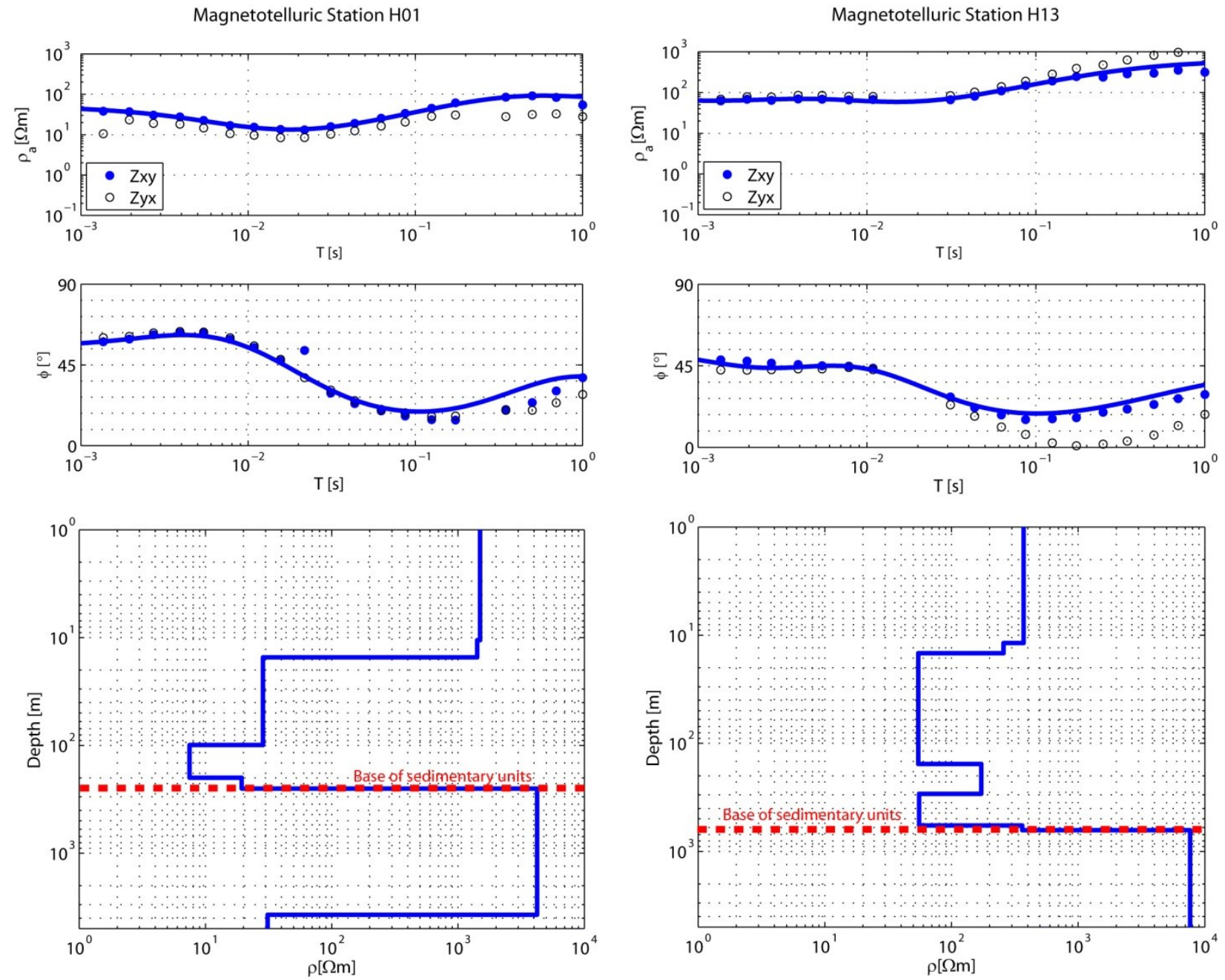

Figure S1: Magnetotelluric data and models for the station H01 (left) and H13 (right). The upper panels show the apparent resistivity curves observed (blue dots) and modeled (blue lines). In the middle, the panels show the phase curves observed (blue dots) and modeled (blue lines). The bottom panels correspond to the resistivity-depth models (blue line) where the base of interpreted sedimentary units (basement) is shown in red. 
Based on the magnetotelluric resistivity-depth models, we constrain the gravity regional for the northern profile. Keeping constant the densities, the preferred regional corresponds to the plane that generates a residual gravity which explains the depths of the sedimentary units observed in the magnetotelluric models (Figure S2).

a)

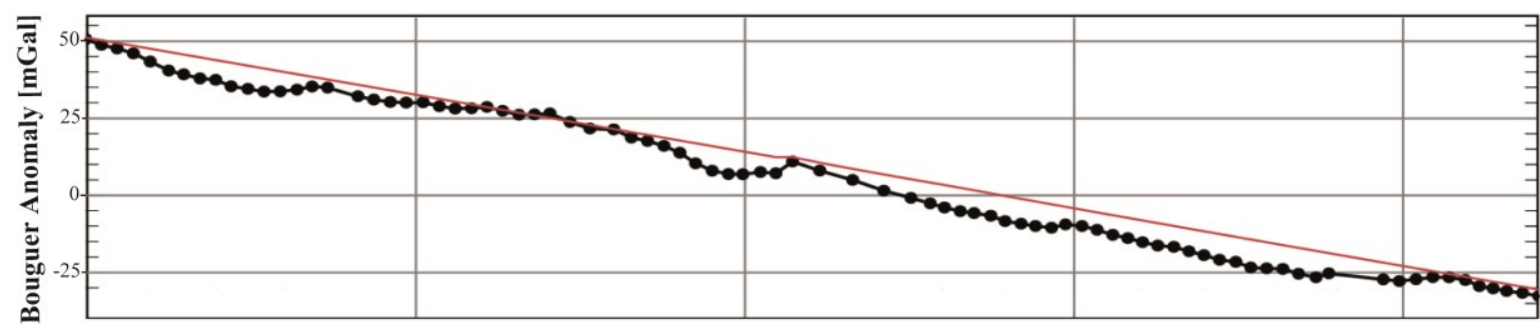

b)

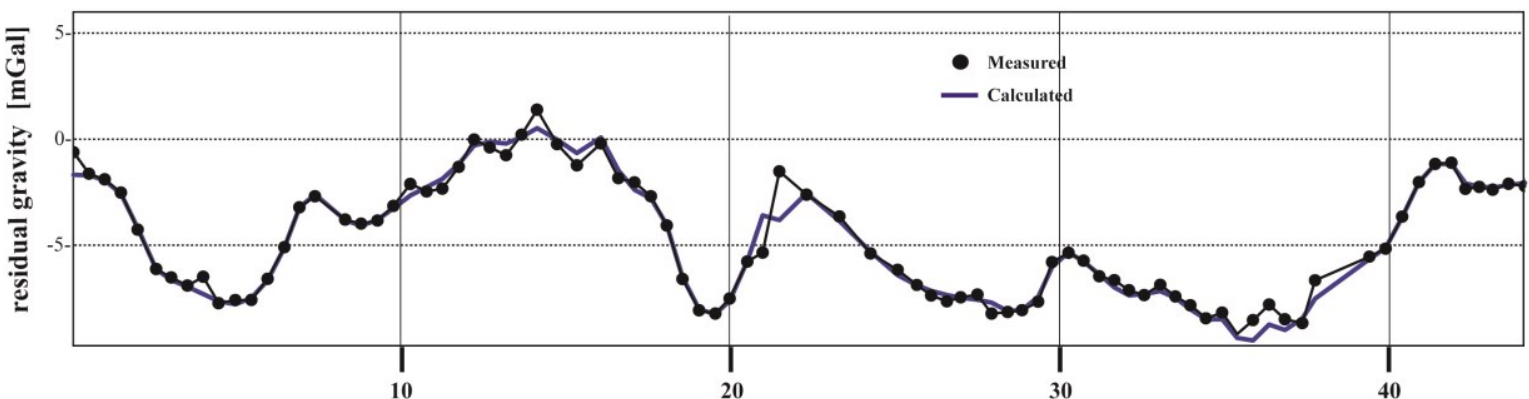

c)

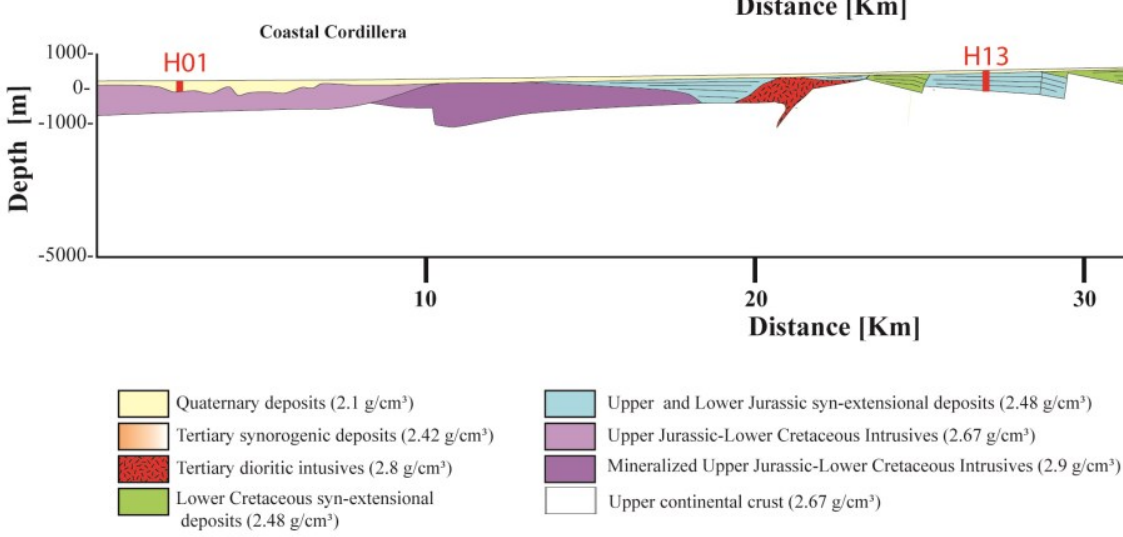

Figure S2: Gravity profile A-A' (see location in Figures 3 and 9 in the main text) a) Observed Bouguer anomaly along the A-A' profile. Black dots correspond to gravity data and red line is the interpreted gravity regional. b) Observed residual gravity and gravity model. Black dots correspond to gravity data and blue line shows the calculated gravity c) Density model constrained with field, gravity and magnetotelluric data. Red lines show the thickness of sedimentary units interpreted in the magnetotelluric stations H01 and H13. 


\section{Sensitivity of the Gravity Regional}

The gravity regional in the northern profile was constrained by the magnetotelluric models. In the case of the southern profile, the gravity regional was selected to obtain the same basement depth in the eastern limit $(200 \mathrm{~m})$ that the obtained for the northern profile. The western limit in both profiles was registered near the basement outcrops.

It is important to note that the main geometric characteristics of the modeled basin remain clear, even considered large changes in the gravity regional. Figures S3 and S4 show different models for the two sections, where the eastern limit of the regional is modified. As we can see, the general geometry of the basins is similar, which implies that regardless the thicknesses, the tectonic interpretation is basically the same. 


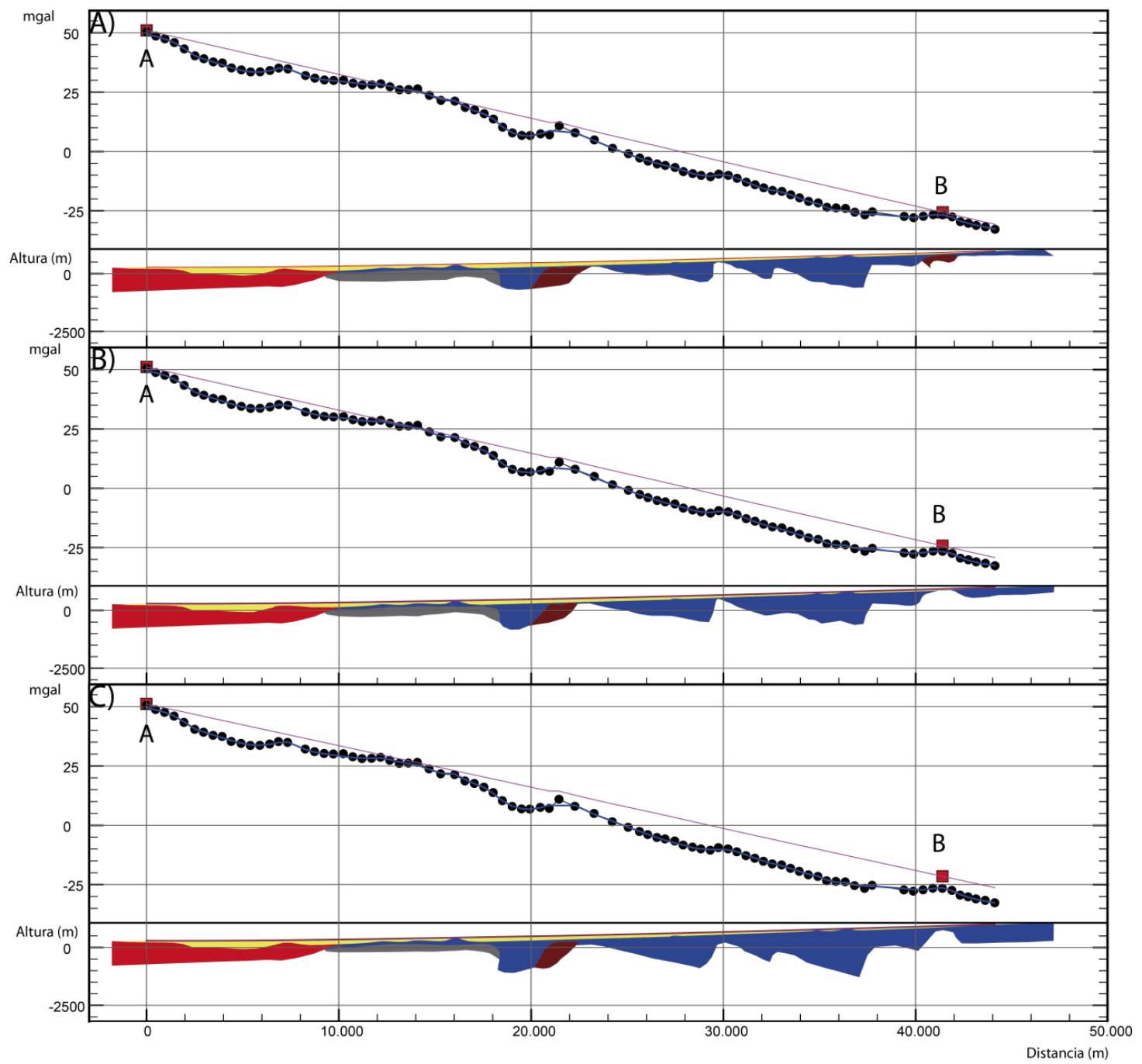

$2.1 \mathrm{~g} / \mathrm{cm}^{3}$ $2.48 \mathrm{~g} / \mathrm{cm}^{3}$ $2.9 \mathrm{~g} / \mathrm{cm}^{3}$ $2.67 \mathrm{~g} / \mathrm{cm}^{3}$

Figure S3: Sensitivity analysis of the gravity regional for the profile A-A' a) Preferred gravity model along the profile. In the upper panel, black dots correspond to gravity data and magenta line is the preferred gravity regional, the calculated gravity is shown in blue. The lower panel presents the density units obtained after the modeling process. The density color scale is indicated to right of the figure. b) Gravity model for a regional $2.5 \mathrm{mGal}$ higher in the east than the observed in the preferred model. All the graphic elements are the same that in a). c) Gravity model for a regional $5 \mathrm{mGal}$ higher in the east than the observed in the preferred model. All the graphic elements are the same that in a). 


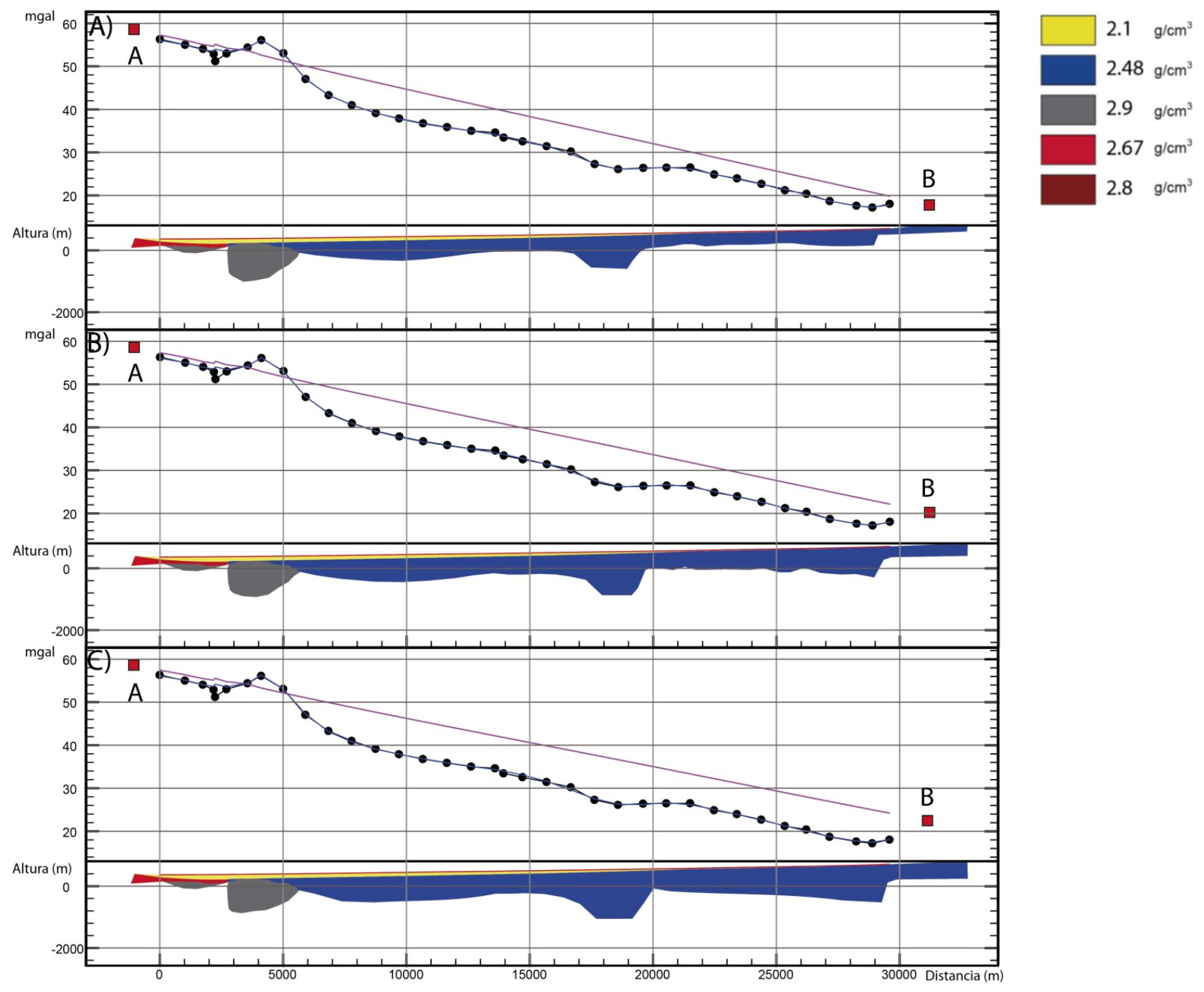

Figure S4: Sensitivity analysis of the gravity regional for the profile A-A' a) Preferred gravity model along the profile. In the upper panel, black dots correspond to gravity data and magenta line is the preferred gravity regional, the calculated gravity is shown in blue. The lower panel presents the density units obtained after the modeling process. The density color scale is indicated to right of the figure. b) Gravity model for a regional $2.5 \mathrm{mGal}$ higher in the east than the observed in the preferred model. All the graphic elements are the same that in a). c) Gravity model for a regional $5 \mathrm{mGal}$ higher in the east than the observed in the preferred model. All the graphic elements are the same that in a). 